\title{
NUMERICAL SIMULATION OF TRADITIONAL TIMBER-MASONRY BUILDINGS SUBJECTED TO LATERAL LOADS
}

\author{
BELÉN JIMÉNEZ ${ }^{1 *}$ AND LUCA PELÀ ${ }^{1}$ \\ ${ }^{1}$ Department of Civil and Environmental Engineering \\ Universitat Politécnica de Catalunya (UPC-BarcelonaTech) \\ Jordi Girona 1-3, 08034 Barcelona, Spain \\ e-mail: maria.belen.jimenez@upc.edu, luca.pela@upc.edu
}

Keywords: Nonlinear Static Analysis, Timber Frame, Unreinforced Masonry, Numerical Simulation, Lumped Plasticity Models, Macro-Mechanical FE Models

Abstract. Existing heritage buildings are often composed of diverse structural typologies,
representing a challenge for structural analysis. This work investigates the use of nonlinear
static analysis to assess the seismic behaviour of hybrid timber-masonry buildings. The
proposed methodology includes the use of Lumped Plasticity Models (LPM) and Macro-
Mechanical Finite Element (FE) approaches to simulate the response of structures composed
of timber frames and masonry walls. Benchmark experiments on timber and masonry specimens
subjected to lateral loads are used to calibrate the constitutive laws governing the behaviour
of the proposed models. The calibrated models are used to appraise the seismic response of an
existing timber-masonry building located in the historical centre of Valparaiso (Chile). The
results predict the nonlinear acceleration-displacement capacity of the buildings, as well as the
expected damage of the structure, revealing the potential local and global failure mechanisms.

\section{INTRODUCTION}

Hybrid timber-masonry buildings represent a significant amount of the built heritage in seismic prone territories. Past earthquakes demonstrated the good performance of these types of structures against seismic loads, especially for the case of the timber frame typologies. However, the study of hybrid structures is often compromised by a high number of uncertainties due to the variety of the structural typologies, the nature of materials, the complexity of the connections or any singularity, which may influence the response of the structure.

Numerical analyses are increasingly used to assess the seismic behaviour of existing buildings. Available modelling strategies usually deal with timber or masonry structures 
separately for the case of homogeneous building typologies. Few research studies could address the modelling of heterogeneous timber-masonry structures in the available literature $[1,2]$.

This research contributes to develop a systematic methodology for the nonlinear static analysis (NSA) of hybrid timber-masonry structural systems subjected to lateral loads. The models were developed with the structural earthquake engineering software SAP2000 v20. The methodology involves a preliminary study of different benchmark experiments used to calibrate the models. An experimental campaign considering bare frame and infilled frame specimens of the Pombalino typology [3] were selected for the numerical calibration of the FE models. A Lumped Plasticity Model (LPM) was proposed for the NSA of timber frame structures. The LPM assumes that nonlinear behaviour is lumped in springs at the members' ends, i.e. where the connections are located, while the timber elements are idealized by using linear elastic isotropic material properties. The infill within the frame was modelled employing the Equivalent Strut Method (ESM). This simplified approach idealizes the infill with a diagonal strut with in-plane strength and stiffness equivalent to that of the uncracked solid masonry panel. Two experimental tests on unreinforced masonry (URM) walls loaded in-plane [5] and out-of-plane [6] were selected to calibrate the macro-mechanical FE models. Such an approach idealized the masonry as a homogeneous material, making no distinction between their components, $[7,8]$. The nonlinear constitutive law of the masonry material is based on the model proposed by [16], defining the stress-strain behaviour and failure criteria.

The seismic behaviour of a hybrid timber-masonry building existing in the historical centre of Valparaíso (Chile) was simulated using the calibrated models, combining LPMs and macro-

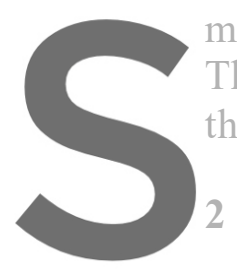
mechanical FE models The NSA applied in the the structure, as well (1) CALIBRATION OH
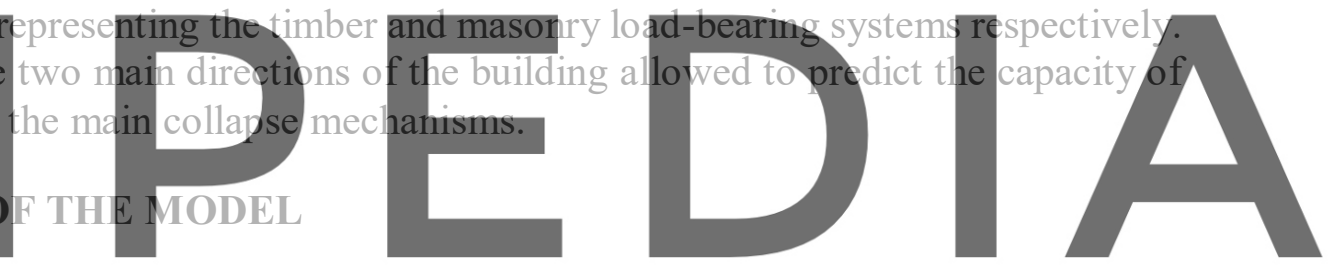

3.2 Numerical simulation of experiments on timber frames

Register for free ath httibs/fwww. scipe dia, com to downdoad the version without the watermark

experimental tests on a bare frame, and an infilled frame of a Portuguese Pombalino wall tested under lateral loads [3]. Both specimens were composed of a main frame of posts and beams braced with St Andrew's crosses, as shown in Figure 2b. Half-lap carpentry joints connected the post and beams of the frame, as well as the diagonals between them, while nails connected the diagonal at the inner sides of main frame elements. The proposed LPM concentrated the nonlinear behaviour of the connections at the ends of the frame members by using either nonlinear hinges or nonlinear springs.

Figure 1a displays the experimentally obtained moment-rotation law of the half-lap connection, as derived from the experimental tests reported in [3]. Nonlinear rotational hinges were assigned at each half-lap connection within the main frame. Due to the lack of experimental data for the diagonal connection, sensitivity analyses were developed to define its axial nonlinear stiffness. Linear elastic models were used to determine the stiffness of the connection by decreasing this value up to reach a good agreement with the global stiffness of 
the model. The axial linear stiffness of the connection was estimated as $9050 \mathrm{kN} / \mathrm{m}$. Subsequently, nonlinearities were integrated into the model by defining the maximum capacity of the connection, estimated as $26 \mathrm{kN}$ by performing sensitivity analyses according to the procedure reported in [4]. The deformational relationship governing the response of the connection was defined with an initial linear behaviour up to the maximum capacity, followed by a softening branch, as shown in Figure $1 \mathrm{~b}$. The yield displacement of the model $d_{\mathrm{y}}$ was determined following the Equation (1):

$$
d_{y}=F_{y} / k
$$

Where $F_{y}$ is the maximum capacity and $k$ is the obtained linear stiffness. The ultimate displacement was assumed as the same reached by the half-lap connection in the test $(0.05 \mathrm{~m})$, when the central connection failed and the remaining connections no longer worked [3]. Nonlinear axial springs were assigned at each node where the diagonals meet the panel. Moment releases were assigned at the ends of the diagonals to avoid transmission of bending moment to these elements. Linear elastic frame elements were used to represent the timber members using the isotropic linear elastic material properties of the timber specimen specified in [3]. A vertical pre-compression of $25 \mathrm{kN}$ at each post of the frame and a horizontal displacement of $0.1 \mathrm{~m}$ at the top beam were applied to simulate the loading conditions of the experiment. The global stiffness of the panel, calculated as $2.60 \times 10^{3} \mathrm{kN} / \mathrm{m}$, and the maximum capacity, equal to $55 \mathrm{kN}$, were properly captured by the model, as shown in Figure 2a. The local and global collapse mechanisms predicted by the model were also in accordance with those

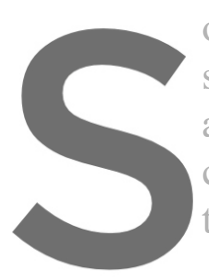
occurred in the experiment. The structure ente
springs at the end of the diagonals reached the
at the centre of the panel experimented a
compression, leading to the ultimate capacity
total collapse of the frame.
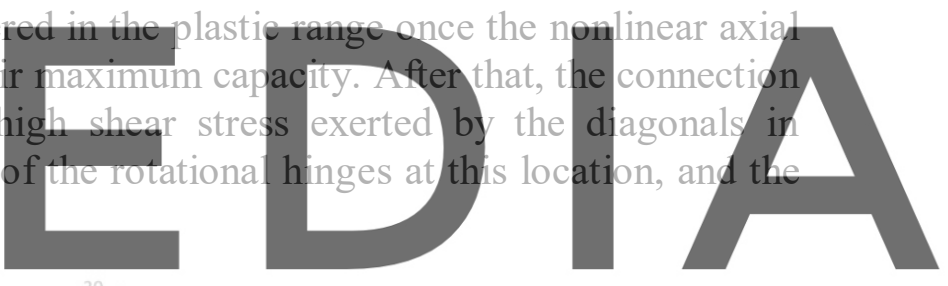

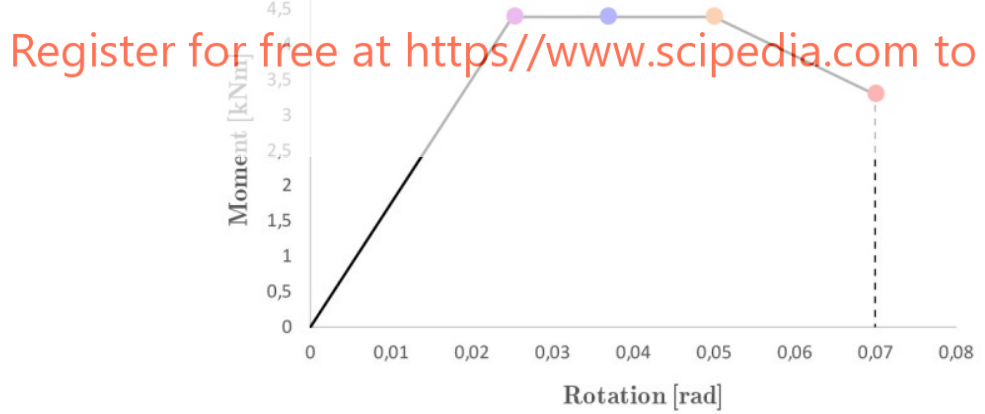

(a)

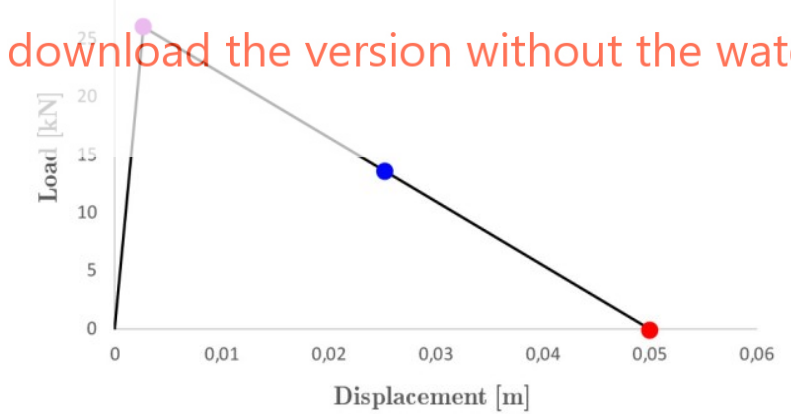

(b)

Figure 1: Nonlinear relationships for the connections in the LPM of the Pombalino frame: (a) Half-lap and (b) diagonals. 


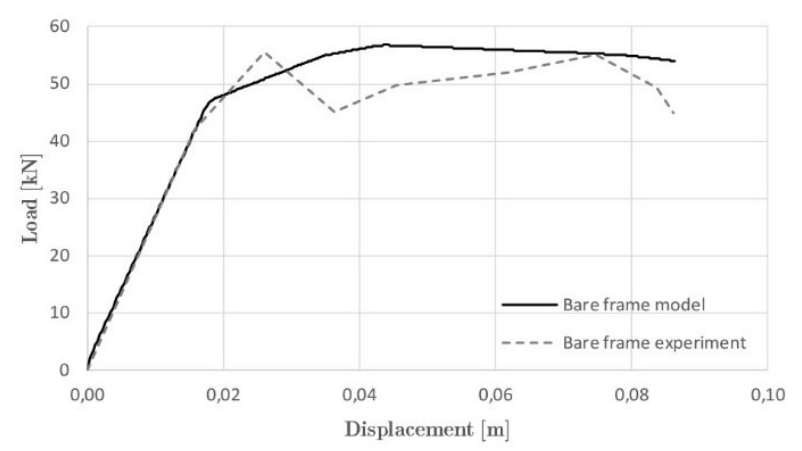

(a)

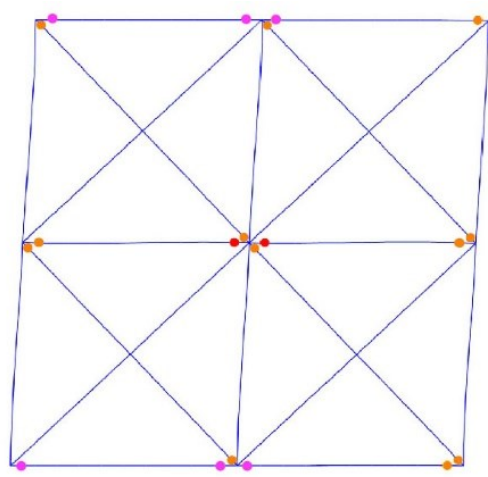

(b)

Figure 2: Results of bare frame with the lumped plasticity model: (a) numerical vs experimental capacity curves and (b) collapse mechanisms.

The influence of the infill in the response of the timber frame specimen was simulated applying the ESM proposed by $[9,10]$. The ESM assumes that the contribution of the masonry infill panel can be represented by an equivalent compression strut of width $\omega$ given by Equation (2).

$$
\omega=\left(\frac{k_{1}}{\lambda_{h}}+k_{2}\right) d
$$

Where $\omega$ is the width of the frame, in $m, d$ is the diagonal length of the infill panel, in $m$, and

$\lambda_{h}$ is a relative stiffnes dependent of $\lambda_{h}$ as reported in
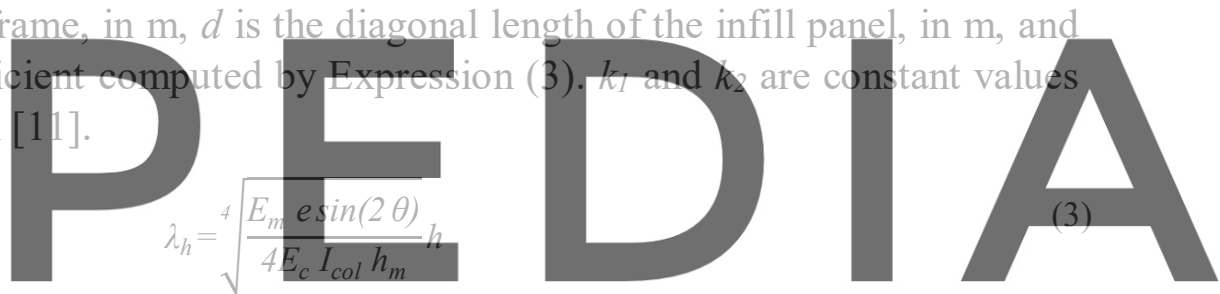

Where $E_{\mathrm{m}}$ is the elastic equivalent modulus of the complete cracking stage on the infill, in

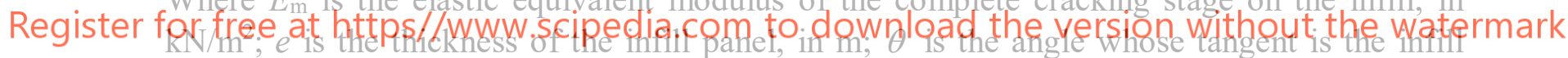

height-to-length aspect ratio, in rad; $E_{\mathrm{c}}$ is the expected modulus of elasticity of the frame material, in $\mathrm{kN} / \mathrm{m}^{2} ; I_{\mathrm{col}}$ is the moment of inertia of the columns, in $\mathrm{m}^{4} ; h_{\mathrm{m}}$ is the height of the infill panel, in $\mathrm{m}$; and $h$ is height of the column measured between centre lines of the beams, in m.

The nonlinear deformation acceptance criterion of the equivalent strut was determined following the methodology described in $[11,12]$. The lateral load-displacement relationship defined in [11] was adopted to determine the deformational control-scheme of the panel. The stiffness of the strut $k_{\mathrm{mfc}}$ corresponding to the complete cracking stage is given by Equation (4).

$$
k_{m f c}=\frac{E_{m} e \omega}{d}
$$

The resistance of the panel is simulated by an equivalent failure compressive strength $\left(\sigma_{\mathrm{br}}\right)_{\min }$ which considers the most probable failure mode that may occur in both conventional tests and 
real structures subjected to seismic action, as detailed in [11]. The lateral strength of the equivalent strut $H_{\max }$ is given by Equation (5).

$$
H_{\max }=\left(\sigma_{b r}\right)_{\min } \text { e } \omega
$$

The stiffness coefficient $\lambda_{h}$ of the equivalent strut for the infill frame panel was 12.3 considering the geometrical and mechanical properties of the materials defined in [3]. The width of the strut was calculated as $0.21 \mathrm{~m}$ considering the coefficients $k_{1}$ and $k_{2}$ equal to 0.47 and 0.04 respectively. The linear stiffness of the panel $k_{\mathrm{mfc}}$ was calculated as $49740 \mathrm{kN} / \mathrm{m}$ by applying Expression (4). A characteristic shear diagonal tension failure mode was predicted for the panel with $\left(\sigma_{\mathrm{br}}\right)_{\min }$ equal to $240.9 \mathrm{kN} / \mathrm{m}^{2}$. Lastly, the maximum lateral strength $H_{\max }$ resulted as $5.56 \mathrm{kN}$. Figure 3 displays the obtained load-displacement relationship of the strut based on [12]. The equivalent strut is modelled using linear elastic frame elements pin-connected to the surrounding frame to avoid rotation resistance. Nonlinearities are introduced into the model at the end nodes of the strut using nonlinear axial hinges defined with the load-deformation relationship shown in Figure 3.

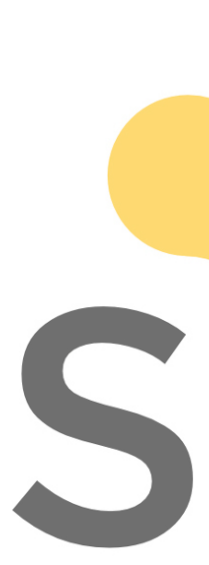

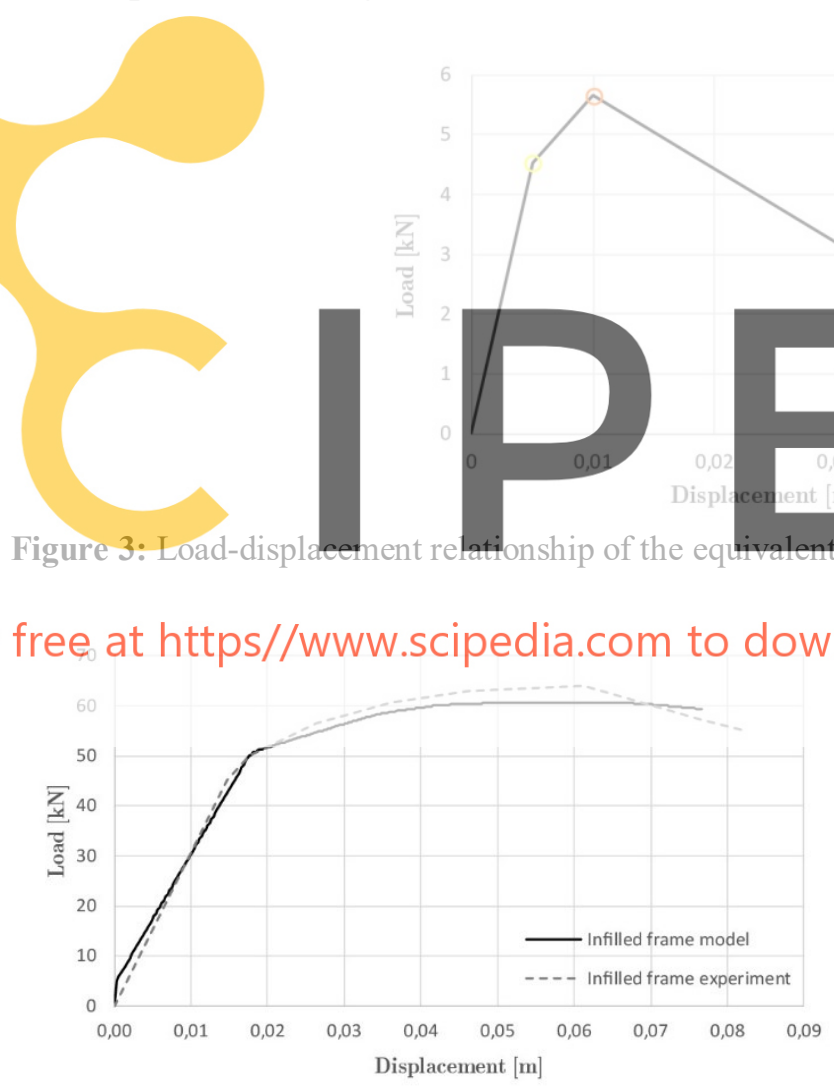

(a)

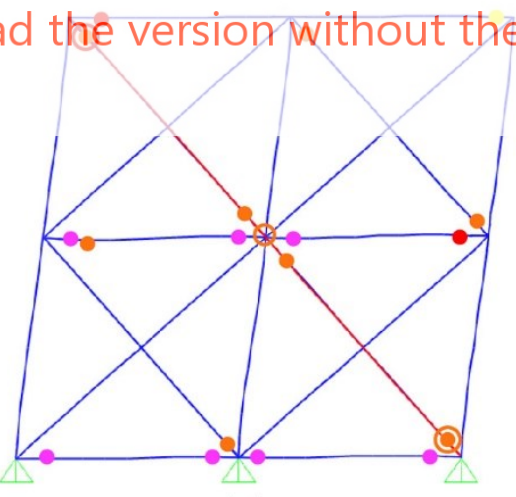

(b)

Figure 4: Results of infilled frame with the lumped plasticity model: (a) numerical vs experimental capacity curves and (b) hinges developed. 
Figure 4a compares the experimental load-displacement capacity curve with that predicted by the LPM of the Pombalino infilled frame. The model captures properly the global stiffness of the frame, and the maximum capacity is slightly underestimated as shown in Figure 4a. The nonlinearities started to appear when the axial springs of struts and diagonals reached their maximum compressive capacity at the displacement of $0.018 \mathrm{~m}$. After this phase, a progressive failure of the rotational hinges in the main frame occurred until the global collapse of the frame (see Figure 4b). This prediction is consistent with what occurred in the experiment, when the diagonals separated from the main frame inducing the first loss in stiffness, followed by the collapse of the half-lap connections.

\subsection{Numerical simulation of experiments on masonry walls}

The calibration of the masonry models was developed by simulating two benchmark experiments of in-plane and out-of-plane loaded URM panels. Macro-mechanical FE models were prepared by applying the shell formulation available in the SAP2000 environment. The shells are four-node formulation objects configured by four-point numerical integration to compute the stiffness, and 2-by-2 Gauss integration points to evaluate the stresses, internal forces, and moments at the nodes. This formulation combines membrane and plate behaviour in planar or three-dimensional structures simulating the in-plane and out-of-plane behaviours [13]. Layered shell sections allow the integration of the material nonlinearities in all of the three membrane stress components of each layer. The material model adopted for the simulation of masonry is based on the Darwin-Pecknold theory [14] and the Vecchio-Collins behaviour [15] available in SAP200d code. The mode represents the compression cracking and the shear behaviour considering pro crack model considers relationship has been $c$ tensile response is defin behaviour. The compressive behaviour of masonry is determined considering the analytical Register for free at https/4www.scipedia.com Eto downiload the version without the watermark

$$
\frac{f_{m}}{f_{m}^{\prime}}=A \frac{\varepsilon_{m}}{\varepsilon_{m}^{\prime}}-B\left(\frac{\varepsilon_{m}}{\varepsilon_{m}^{\prime}}\right)^{C}
$$

Where $f_{\mathrm{m}}$ and $\varepsilon_{\mathrm{m}}$ are the compressive stress and strain in masonry respectively, and $\varepsilon_{\mathrm{m}}^{\prime}$ is the peak strain corresponding to $f^{\prime} \mathrm{m} \mathrm{A}, \mathrm{B}$, and $\mathrm{C}$ are coefficients describing the shape of the curve, being $\mathrm{A}=6.4, \mathrm{~B}=5.4$ and $\mathrm{C}=1.17$ [17]. The Coulomb friction model of the material is considered as follows:

$$
\tau=c+\sigma \tan \varphi
$$

Where $c$ is the cohesion, $\sigma$ is the normal stress and $\tan \varphi$ is the friction between the elements. A friction angle $\varphi$ equal to $23^{\circ}$ was used to define the shear model as recommended in $[17,18]$. The FE model is discretized considering a mesh formed by 258 rectangular shell elements of $0.18 \times 0.28 \mathrm{~m}^{2}$ and 310 nodes. The section of the shells was defined with only one layer of 0.31 $\mathrm{m}$ thickness, and four integration points along the thickness direction. Figure 5 shows the uniaxial compression-tension constitutive laws of masonry as defined by the material properties 
obtained in [5]. The compressive stress-strain relationship was modified considering a perfectly plastic behaviour (dashed line in Fig. 5a) as suggested in [17], in order to allow the model to reproduce correctly the base rotation of the piers in the experiment. A vertical pre-compression of $200 \mathrm{kN}$ was applied at each pier of the wall, followed by a lateral displacement of $0.03 \mathrm{~m}$ applied at a height of $3.00 \mathrm{~m}$ on the left side of the wall simulating the experimental loading conditions. All the nodes at the base were restrained in all the DOFs to reproduce the rigid support conditions. NLA was performed to capture the initial yielding and plastic behaviour of the model, and compute the load-displacement curve.

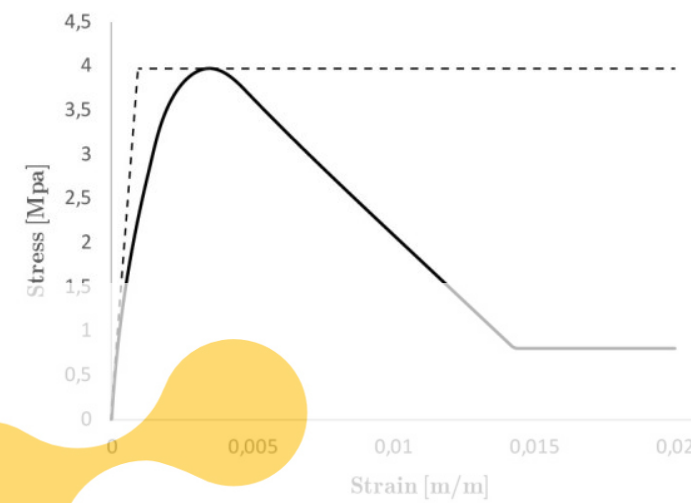

(a)

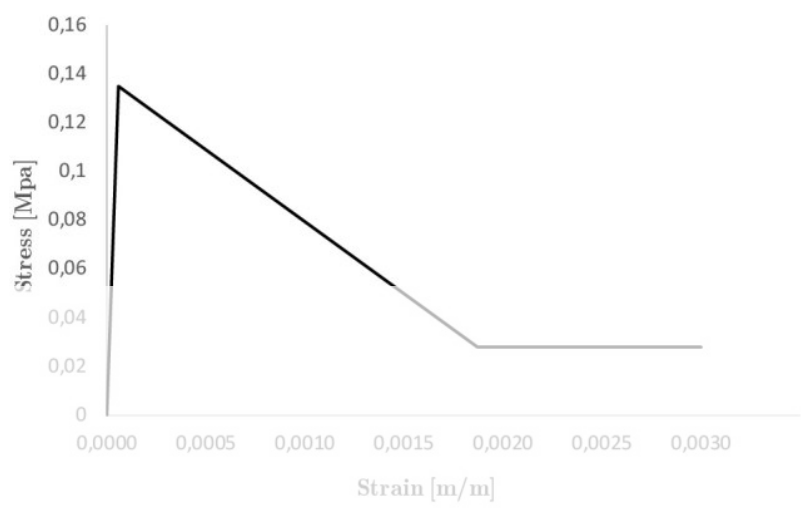

(b)

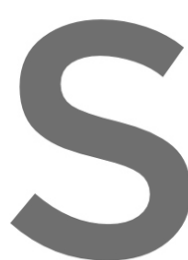

\section{Figure 5: Stress-strai \\ Figure 6a compares predicted by the model capacity. The formation correctly the failure nechanisms occurred in}
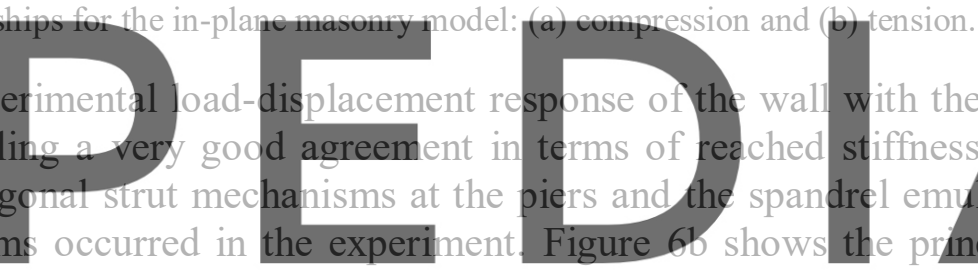

compressive strain contour of the wall at the end of the test, with the residual resisting

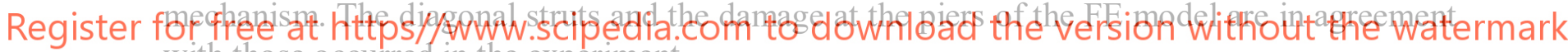
with those occurred in the experiment.

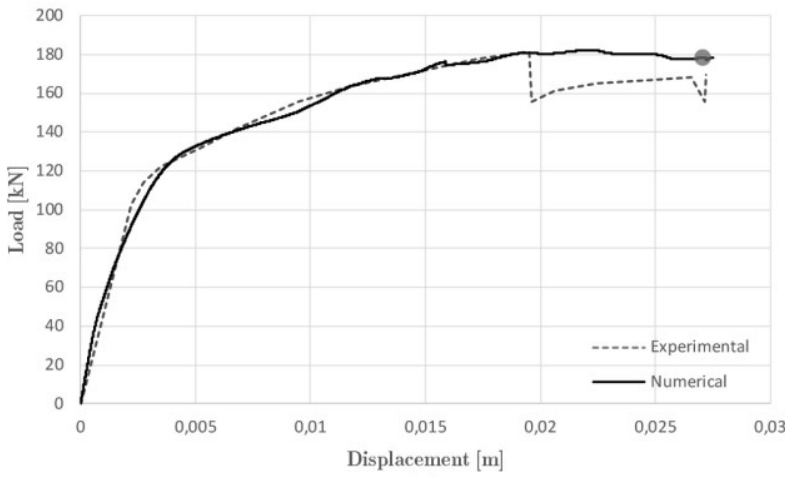

(a)

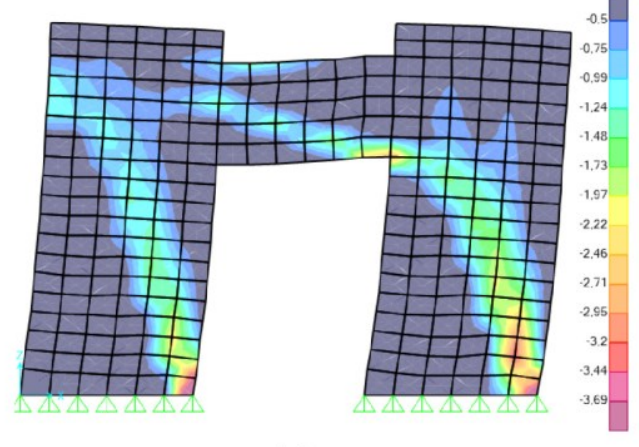

(b)

Figure 6. In-plane loaded masonry model results: (a) capacity curve and (b) principal compressive strain contour. 
The masonry wall tested under out-of-plane loads [6] corresponds to a solid specimen without openings of $4.00 \mathrm{~m}$ width $\times 2.5 \mathrm{~m}$ height $\times 0.11 \mathrm{~m}$ thickness. Return walls of $0.45 \mathrm{~m}$ length were built-in at both sides of the specimen to provide a realistic full moment contact along the vertical edges. The wall was subjected to a vertical precompression of $100 \mathrm{kN} / \mathrm{m}^{2}$ at the top of the wall, followed by a uniform pressure applied under displacement control at the surface of the panel. Given the symmetrical layout of the specimen, only half part of the wall was modeled considering appropriate symmetrical boundary conditions. The model was discretized into 240 shell elements of $0.15 \times 0.15 \mathrm{~m}^{2}$. The section of the shells was set with one layer of $0.11 \mathrm{~m}$ and five integration points along the thickness direction. Figure 7 shows the uniaxial compression-tension constitutive laws for masonry considering the mechanical properties obtained by [6].

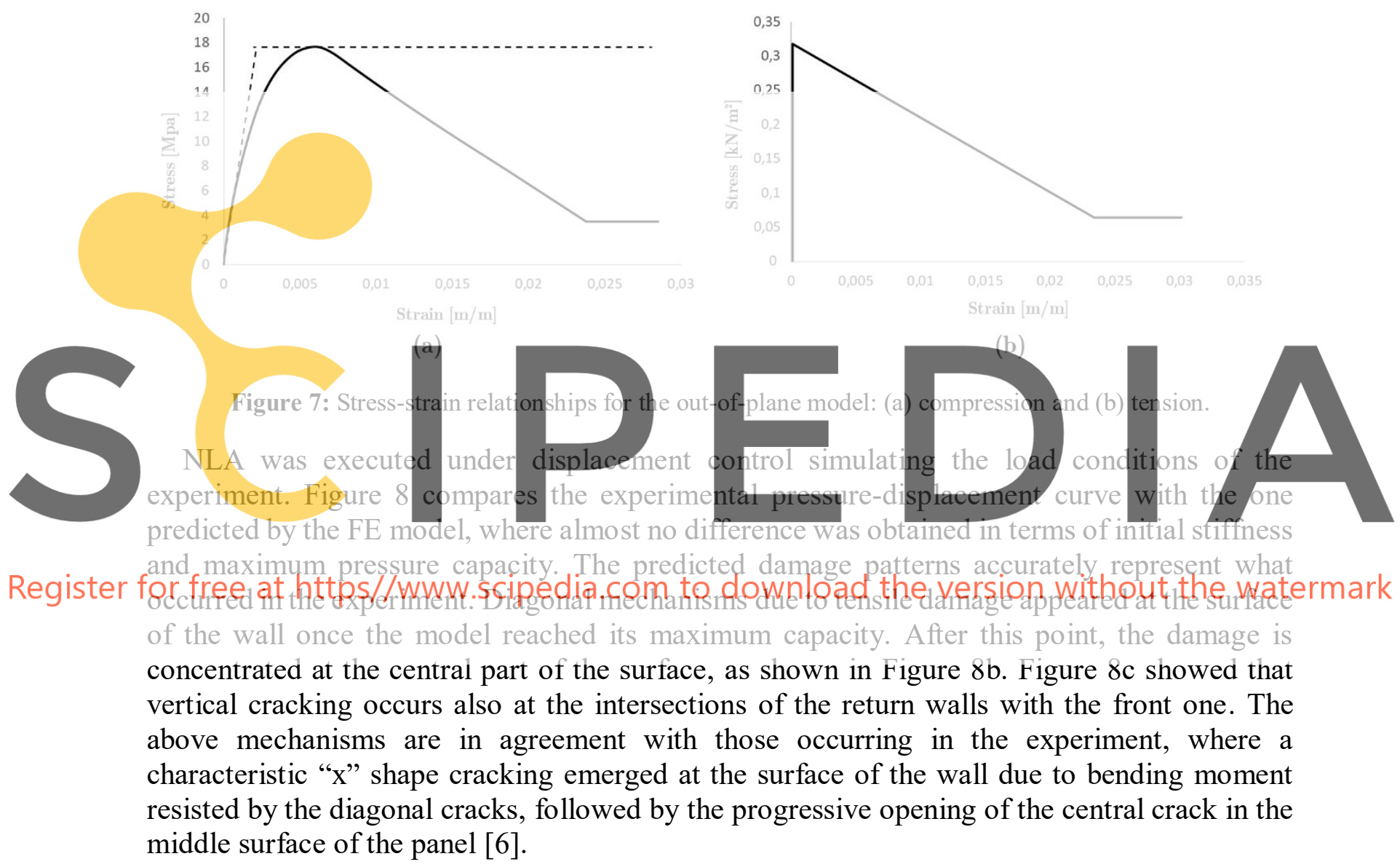




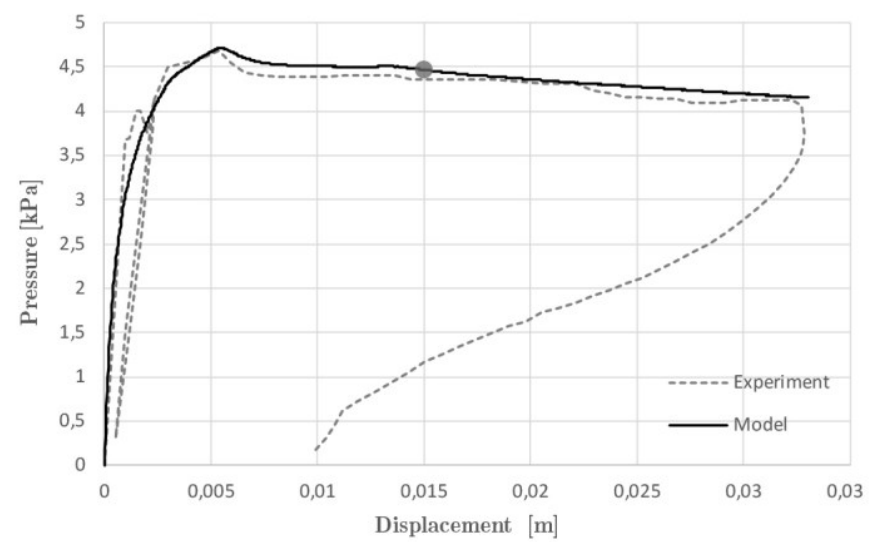

(a)

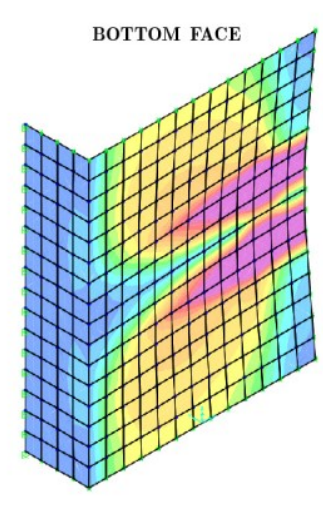

(b)

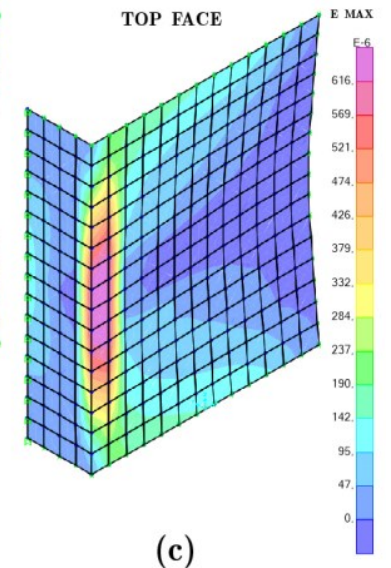

(c)

Figure 8: Out-of-plane loaded masonry model results: (a) capacity curve and (b-c) principal tensile strain contour after reaching the maximum load (horizontal displacement of $0.015 \mathrm{~m}$ ).

\section{SEISMIC ASSESSMENT OF A HYBRID TIMIBER-MASONRY BUILDING}

The calibrated models were used to evaluate the seismic capacity of a hybrid timber-masonry building existing in the historical centre of Valparaíso (Chile). The case-study is composed of timber frame structure following the platform-frame configuration, while two perpendicular sidewalls are made of URM. The timber frame walls are constituted by stud elements of $0.1 \times$

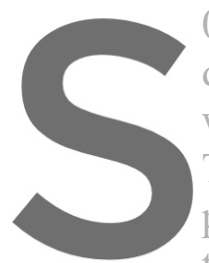
$0.1 \mathrm{~m}^{2}$ cross-section, diagonal elements. The while the diagonals arte The storeys are composed of joists of $0.12 \times$ perpendicularly betwde their elevation, decreasing thei
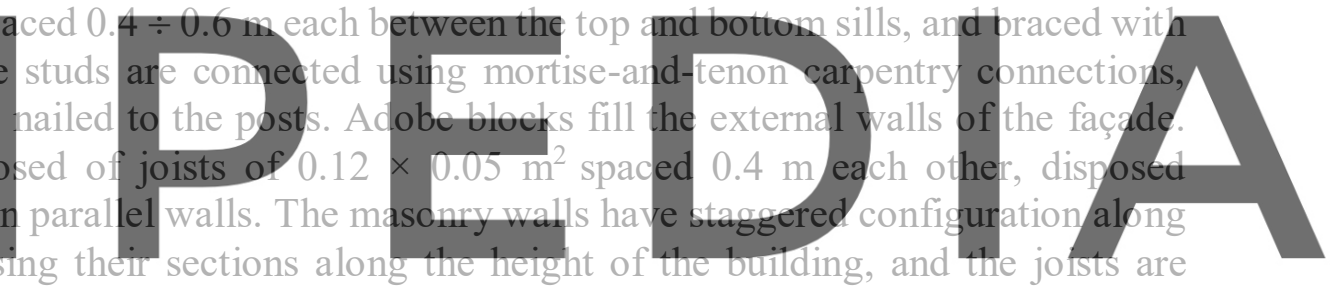
embedded within the masonry bricks.

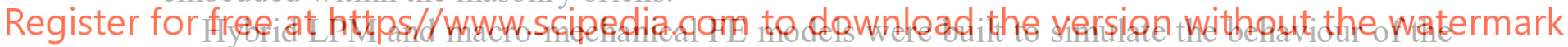

building under lateral loads. The characteristic mechanical properties of the oak timber were used to define the frame elements. The maximum bending moment of the mortise-and-tenon connection was estimated based on the theoretical model proposed by [19] as $3.6 \mathrm{kNm}$. The moment-rotation backbone was assumed to be the same as the half-lap model already calibrated in the simulation of the Pombalino frame. Lastly, the diagonal connection was assumed to have the same behaviour of the connection by contact in the Pombalino model too, since they present equivalent configuration and geometry. Nonlinear rotational hinges and axial springs were used to represent the mortise-and-tenon and diagonal connections within the frame, respectively. The material model of masonry was defined using the characteristic mechanical properties of URM proposed by [20].

The results demonstrated that masonry walls had a central role in the lateral response of the building since they contribute to resist a major part of the applied load. However, the overall ductility of the structural system is strictly dependent on the intrinsic fragility of these structural members. Figure 9 displays the acceleration-displacement relationships predicted by the model, 
while Figure 10 shows the FE results in the $\mathrm{X}$ and $\mathrm{Y}$ directions. In the $\mathrm{X}$ direction, the model entered in the plastic phase once a tensile crack appeared at the base of the overturning masonry wall perpendicular to the applied load (Figure 10a). Some of the axial hinges of the timber frames parallel to the applied load then started to reach their ultimate capacity. In this case, the total collapse of the building was provoked by the global overturning mechanisms around the base of the masonry walls. The analysis in the $\mathrm{Y}$ direction showed the highest stiffness and capacity. In this case, the characteristic global collapse of the model is governed by the shear sliding mechanism formed at the base of the masonry walls parallel to the applied load (Figure $10 \mathrm{~b}$ ), while the hinges of the frame did not reach their ultimate capacity.
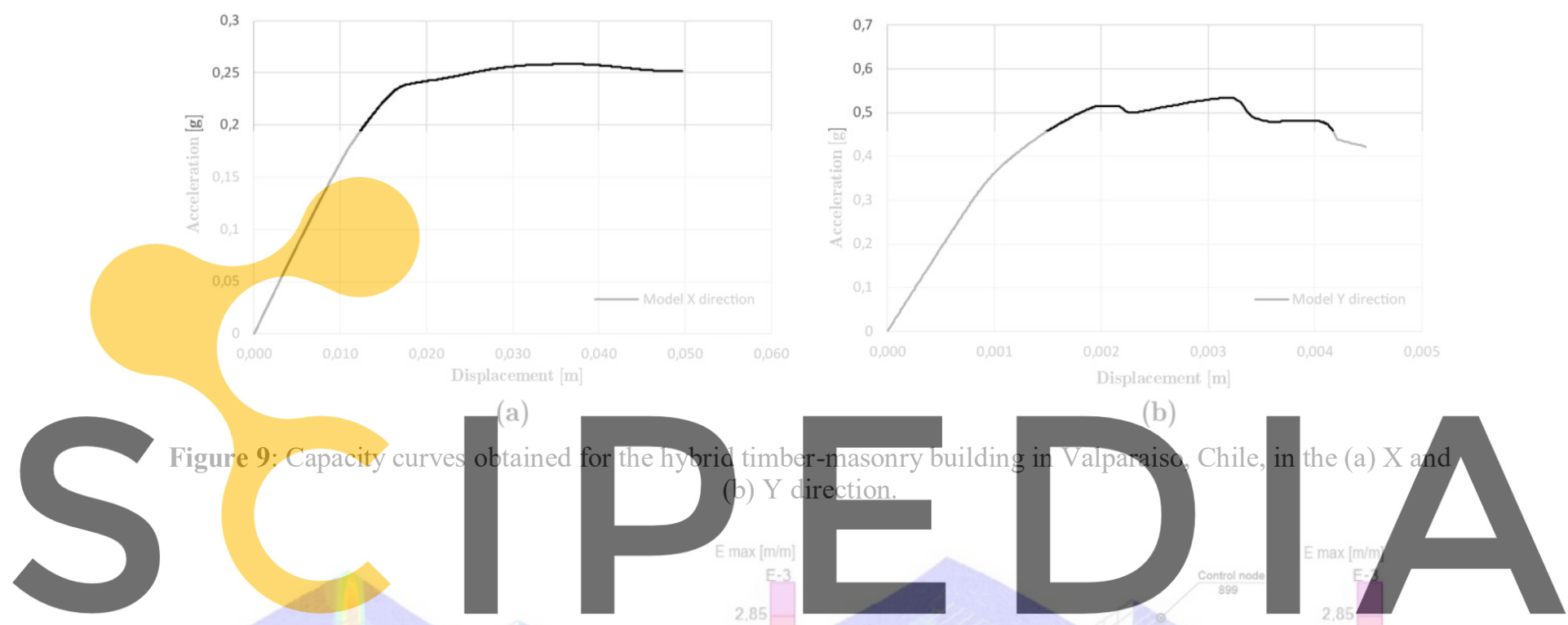

Register for free at https//www.scipedia.com to download the version without the watermark

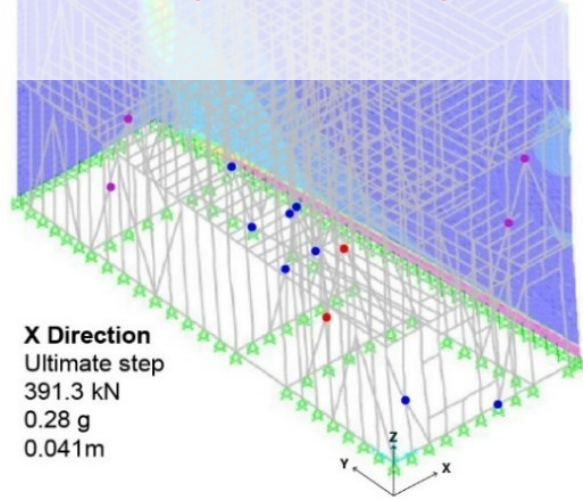

(a)

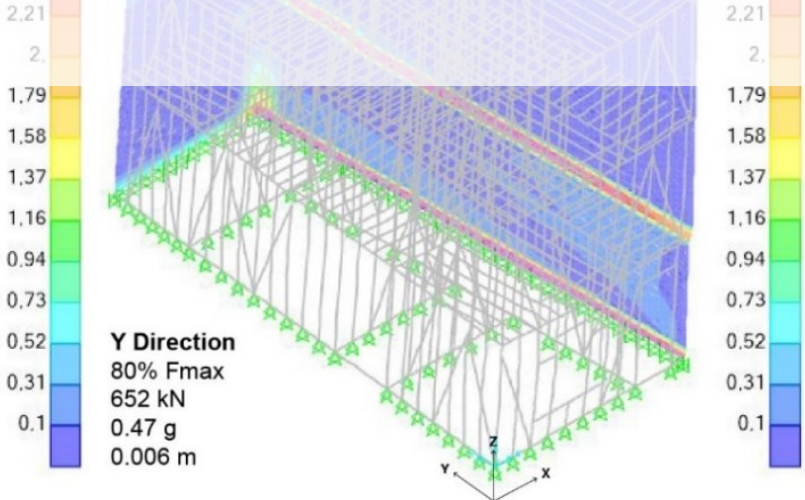

(b)

Figure 10. Seismic analysis of a hybrid timber-masonry building in Valparaiso, Chile along the (a) $\mathrm{X}$ and (b) $\mathrm{Y}$ direction. Principal tensile strain labelled from the maximum to the residual tensile strain capacity, and hinges formation. 


\section{CONCLUSIONS}

This paper has presented a numerical study of timber frame and URM structures subjected to lateral loads, aimed to assess the seismic behaviour of hybrid timber-masonry buildings. A Lumped Plasticity Model (LPM) was calibrated to represent benchmark experiments on timber frames, including infill by means of Equivalent Strut Model (ESM). A macro-mechanical FEM was used to simulate the behaviour of in-plane and out-of-plane loaded masonry tests. The calibrated reference models were used to prepare a hybrid model, including both timber frames and masonry walls, of an existing building located in the historical centre of Valparaíso (Chile). The simulation predicted the collapse mechanisms of the building along its principal directions, showing that masonry walls play an important role in the resisting system. In X direction, the collapse is due to overturning of the largest masonry wall perpendicular to the applied load, with consequent failure of some of the connections in the timber frames. In Y direction, a sliding shear mechanism occurs at the base of the masonry wall parallel to the applied load, with no apparent damage in the timber frame.

Acknowledgements. This research has received the financial support from the ELARCH project (Euro-Latin America partnership in natural Risk Mitigation and protection of the Cultural Heritage), reference number 552129-EM-1-2014-1-IT- ERASMUS MUNDUS EMA21, funded with support of the European Commission. This document reflects the view of the authors, and the Commission cannot be held responsible for any use that may be made of the information contained therein. The authors also gratefully acknowledge the financial support from the Ministry of Science, Innovation and Universities of the Spanish Government (MCIU), the State Agency of Research (AEI), as well as the ERDF (European Regional Development Fund), through the SEVERUS project (Multilevel evaluation of seismic vulnerability and risk mitigation of masonry buildings in resilient historical urban centres, ref. num. RTI2018-099589-B-I00).

\section{REFERENCES}

[1] Ciocci, M.P., Sharma, S., and Lourenço, P. Engineering Simulations of a Super-Complex Cultural Heritage Building: Ica Cathedral in Peru. Meccanica (2018) 53 (7): 1931-58.

[2] Kouris, L.A.S., and Kappos, A.J. Detailed and Simplified Non-Linear Models for TimberFramed Masonry Structures. Journal of Cultural Heritage (2012) 13 (1): 47-58.

[3] Poletti, E. Characterization of the Seismic Behaviour of Traditional Timber Frame Walls. PhD dissertation (2013). Department of Civil Engineering, University of Minho.

[4] Ciocci, M. P. Structural Analysis of the Timber Structure of Ica Cathedral, Peru. MSc Thesis. (2015). Department of Civil Engineering, University of Minho.

[5] Parisi, F., Ivano, I., Balsamo, A., Augenti, N., and Prota, A. In-Plane Behaviour of Tuff Masonry Strengthened with Inorganic Matrix-Grid Composites. Composites Part B: Engineering (2013) 45 (1): 1657-66.

[6] Griffith, M.C., and Vaculik, J. Out-of-Plane Flexural Strength of Unreinforced Clay Brick Masonry Walls. TMS Journal (2007): 53-68 
[7] Endo, Y., Pelà, L., Roca, P., Da Porto, F., Modena, C. Comparison of Seismic Analysis Methods Applied to a Historical Church Struck by 2009 L'Aquila Earthquake. Bulletin of Earthquake Engineering (2015) 13 (12): 3749-78

[8] Pantò, B., Silva, L., Vasconcelos, G., and Lourenço, P. Macro-Modelling Approach for Assessment of out-of-Plane Behaviour of Brick Masonry Infill Walls. Engineering Structures (2018): 529-49.

[9] Stafford-Smith, B. Lateral Stiffness of Infilled Frames. Journal of Structural Division, ASCE (1963) 88 (6): 183-199.

[10] Bertoldi, S.H., Decanini L.D., and Gavarini, C. Telai Tamponati Soggetti ad Azioni Sismiche Un Modelo Semplificato Confronto Sperimentale e Numerico. In $6^{\text {th }}$ Convegno Nazionale L'Ingegneria Sismica in Italia (1993): 815-24.

[11] Decanini, L., Mollaioli, F., Mura, A., Saragoni, R. Seismic Performance of Masonry Infilled R/C Frames. In 13th World Conference on Earthquake Engineering (2004).

[12] Sassun, K., Sullivan T. J., Morandi, P., and Cardone D. Characterising the In-Plane Seismic Performance of Infill Masonry. Bulletin of the New Zealand Society for Earthquake Engineering (2016) 49 (1): 100-117.

[13] CSI. CSI Analysis Reference Manual (2016).

[14] Darwin, D. and Pecknold, D. A. W. Inelastic Model for Cyclic Biaxial Loading of Reinforced Concrete. Civil Engineering Studies SRS-409 (1974), University of Illinois, Urbana Champaign, Illinois.

[15] Vecchio, F.J. and. Collins, M. P. The Modified Compression-field Theory for Reinforced Concrete Elements Subjected to Shear. ACI Journal Proceedings (1986) 83 (2): 219-31.

[16] Kaushik, H. B., Rai D. C., and Jain, S. K. and ASCE, M. Stress-strain Characteristics of Clay Brick Masonry under Uniaxial Compression. Journal of Materials in Civil Engineering (2007) 19 (9): 728-39.

[17] D’Ambra, C., Lignola, G. P. and Prota, A. Multi-Scale Analysis of In-plane Behaviour of Tuff Masonry. The Open Construction and Building Technology Journal (2016) 10:135151.

[18] CEN. 2005. EN 1996-1-1: Eurocode 6: Design of Masonry Structures - Part 1-1: General Rules for Reinforced and Unreinforced Masonry Structures.

[19] Chen, C., Qiu, H. and Lu, Y. Flexural behaviour of timber dovetail mortise-tenon joints. Construction and Building Materials (2016) 112: 366-377.

[20] NTC. Circolare 21 Gennaio 2019 n. 7 C.S.LL.PP. Istruzioni per l'applicazione Dell'aggiornamento Delle 'Norme Tecniche per Le Costruzioni' Di Cui Al D.M. 17/01/2018." Consiglio Superiore Dei Lavori Pubblici. 